\title{
La reconfiguración como el modo de llegar a ser. Surgimiento de los centros de detención y/o tortura en el Chile dictatorial ${ }^{1}$
}

\section{The reconfiguration as the way to become. Emerging of the detention and/or torture centers in the dictatorial Chile}

\author{
José Santos Herceg \\ Instituto de Estudios Avanzados, Universidad de Santiago de Chile. Santiago, Chile. \\ jose.santos@usach.cl
}

\section{Resumen}

El presente escrito parte propone que el modo en que se constituyen los centros de detención y/o tortura de la dictadura militar chilena es el de la reconfiguración. Por "reconfiguración" se entenderá el proceso por el cual a un inmueble se le altera, por una parte, su finalidad y sentido, y por otra, se interviene su infraestructura. Es así como estadios, universidades, liceos y colegios, hospitales, etc., pasaron a ser parte del enorme contingente de 1.168 centros de detención y/o tortura que operaron durante la dictadura. A la luz de los testimonios de los prisioneros que fueron encerrados en dichos lugares, se intenta establecer la forma en que se les involucró en dichos procesos de reconfiguración y la manera en que esto los afectó, dando lugar a otra forma de suplicio.

Palabras Clave: reconfiguración, detención, tortura, finalidad, infraestructura.

\begin{abstract}
The present document is based on the finding that the reconfiguration its the way in which the detention and/or torture centers are established by the chilean military dictatorship. 'Reconfiguration' means the process by which the property is altered on its purpose and meaning and moreover on its infrastructure. Thus, stadiums, universities, high schools, colleges, hospitals, became part of the huge contingent of 1.168 detention and/or torture centers that operated during the dictatorship. Using the testimonies of prisoners that were confined in such places is intended to establish the way in which they became involved in such process of reconfiguration, and the way in which this affected them, setting up another form of torture.

Keywords: Reconfiguration, Detention, Torture, Purpose, Infrastructure.

1 Este trabajo forma parte de la investigación titulada "Campos prisioneros en Chile. Reconfiguración de los lugares y las subjetividades" (FONDECYT No 1140200).
\end{abstract}


La prisión política, la tortura y la desaparición fueron realidades en todas las dictaduras militares del cono sur. La Escuela de las Américas enseñó sus estrategias a quienes las protagonizaron y el Plan Cóndor las articuló. Pese a la existencia de una matriz común, sin embargo, no en todos los países se aplicó de igual forma y con la misma intensidad. Lo que caracteriza particularmente al caso de Chile fue la privación de libertad masiva de los opositores al régimen y la tortura sistemática y generalizada. Para ello, se contó con al menos 1.168 lugares de prisión, que son los que se conocen hasta hoy. Sobre los centros de prisión y/o tortura² chilenos es poco lo que se ha escrito y solo es posible encontrar trabajos puntuales acerca de algunos lugares emblemáticos ${ }^{3}$, pero sobre los centros desde la perspectiva espacial no hay casi nada publicado. Excepciones son los trabajos de Silva y Rojas, el de Landaeta, el de Pulgar y el de Moret (consultar en la bibliografía).

En esta oportunidad, el acercamiento a los centros de detención y/o tortura será desde la perspectiva de su aparición, su generación y su surgimiento. Cuando se observa el listado de los centros que hubo en Chile salta a la vista, antes que nada, el hecho de que prácticamente ninguno de ellos fue creado explícitamente para ser usado como tal. En el documental titulado Chacabuco, memoria del silencio de Ancelovici (2001), uno de los entrevistados dice, con toda razón, que "los militares nunca construyeron cárceles" sino que "elegían espacios existentes". De hecho, parece relativamente claro que su intención fue siempre esta. Pascal Bonnefoy informa de un plan desarrollado en el Estado Mayor de Defensa Nacional (EMDN) por un grupo de oficiales golpistas, liderados por el vicealmirante de la Armada Patricio Carvajal (10). Este plan habría

2 En lo relativo a la denominación de estos lugares, se ha escogido el de "centro de detención y/o tortura" como un nombre genérico con el objeto de establecer que existieron en Chile diferentes tipos de centros. Hubo algunos destinados solo o principalmente a detener y contener a los prisioneros; hubo otros especialmente habilitados para torturar, a los que eran llevados los prisioneros para interrogarlos y luego ser devueltos a su lugar de detención, y hubo otros en los que se daban ambas prácticas, tanto la detención como la tortura.

3 Villa Grimaldi (Geis, Irene y Pamela Jiles. "Campo de Concentración: Tortura y muerte en la Villa Grimaldi”. Análisis VII (1979): 30-34; Fuenzalida, Nicole. "Villa Grimaldi, análisis de la configuración del espacio y arquitectura, en relación a las estrategias de represión y control de los cuerpos de detenidos y torturados. Hacia una Arqueología de la Represión Política en Chile”. Informe de Práctica Profesional, Departamento de Antropología, Universidad de Chile, 2009), Londres 38 (Landaeta, Romané. "Centros de Tortura en Chile 1973-1990: Aproximaciones hacia una Arqueología del horror. El caso de Londres 38”. Historia y Memoria: Reconstrucciones de la represión en Chile: 1973-1974: El caso de Londres 38. Memoria Universidad Autónoma de Madrid, 2007; Escobar, América. Memoria y materialidad Londres 38: Un estudio de caso. Tesis para optar al título de Antropóloga, Departamento de Antropología y Sociología, Universidad de Concepción, 2011; Lazzara, Michael. "Dos propuestas de conmemoración pública: El Museo de la Memoria y los Derechos Humanos y Londres 38 (Santiago de Chile)”. A contracorriente 3.8 (2011): 55-93; D’Orival, Roberto y Viera Stein. "Londres 38”. Ciudad y Memorias. Desarrollo de Sitios de Conciencia en el Chile actual. Santiago: Corporación Parque por la paz Villa Grimaldi, 2011. 193-199. Impreso.), el Estadio Víctor Jara (San Francisco, Alexander, Miguel Fuentes y Jairo Sepúlveda. "Hacia una arqueología del estadio Víctor Jara: Campo de detención y tortura masiva de la dictadura en Chile (1973-1974)”. Revista de Arqueología Histórica Argentina y Latinoamericana 4 (2010): 91-116; San Francisco, Alexander, Miguel Fuentes y Jairo Sepúlveda. "Espacios de represión, lugar de memoria: El estadio Víctor Jara como centro de detención y tortura masiva de la dictadura en Chile”. Revista Atlántica-Mediterránea de Prehistoria y Arqueología Social 11 (2009): 137-169), Tres Álamos (Camus, María Eugenia. "Puchuncaví, Ritoque, Tres Álamos: La otra cara de los campos de concentración". Análisis XII (1989): 33-37) y el Estadio Nacional (Durán, Carlos. "Estadio Nacional: Memoria Nacional”. Ciudad y Memorias: Desarrollo de sitios de conciencia en el Chile actual. Santiago: Corporación Parque por la Paz Villa Grimaldi, 2011. 148-156; Bonnefoy, Pascale. Terrorismo de estadio: prisioneros de guerra en un campo de deportes. Santiago: Ediciones Chile América (CESOc), 2005). 
estado elaborado desde junio de 1973, e incluía la apertura en Santiago de centros de detención en el Estadio Chile y en el Estadio Nacional. Simultáneamente, se habilitarían también en otras partes del país, como los estadios deportivos de Concepción y Valparaíso, la Isla Dawson (Duodécima Región), Pisagua (Primera Región), Tejas Verdes (Quinta Región), Isla Quiriquina (Octava Región), la Academia de Guerra Naval y los buques Esmeralda, Lebu y Maipo en Valparaíso. En la capital, además de los dos estadios ya mencionados, se utilizarían la Escuela Militar del Ejército y la Academia de Guerra Aérea. Por último, se agregaba transitoriamente el Ministerio de Defensa, la Casa de Cultura de Barrancas, el Instituto Nacional Barros Arana y el Parque Cerrillos (11). El plan no contemplaba ninguna construcción, sino tan solo la ocupación de inmuebles ya existentes.

Como ha escrito Nancy Guzmán, a partir del 11 de septiembre del 1973, "colegios, universidades, casas, hospitales, centros vacacionales, estadios, barcos, clubes deportivos y otros lugares fueron transformados en espacios de destrucción humana y social" (69). Hasta donde he podido rastrear, solo existen tres inmuebles construidos expresamente para servir como lugares de reclusión y tortura. De un total de 1.168 reconocidos, que existan apenas tres que fueron concebidos para estos propósitos habla claramente de una política expresa: la utilización preferente de inmuebles ya existentes.

Lo que se observa en casi la totalidad de los casos es una reconfiguración de lugares. Un número importante era inicialmente casas particulares que fueron transformadas en las llamadas "casas de seguridad": se volvieron "casas de la DINA" y posteriormente "casas de la CNI". Hay también casas de fundos que fueron utilizadas como centros de detención y/o tortura. Y, como dice Guzmán, algo parecido ocurre con algunas clínicas y una serie de edificios públicos y civiles, como centros deportivos, universidades, liceos y colegios, hospitales, estaciones de bomberos, estaciones de trenes y edificios de la administración pública. Junto con ello, hay también instalaciones de los uniformados que se vuelven centros de detención y/o tortura, como unidades militares, unidades de policía e investigación, unidades de Carabineros e incluso algunos barcos. Finalmente, puede mencionarse el caso de las cárceles que, construidas para albergar delincuentes, son utilizadas para encerrar a detenidos políticos.

Con el fin de ser utilizados como centros de detención y/o tortura, estos espacios sufren mutaciones, transformaciones, cambios en diferentes sentidos, que repercuten profundamente en los prisioneros detenidos en ellos. Interesa rastrear su percepción sobre estos procesos. Es por ello que se trabajará principalmente sobre la base los testimonios escritos por las mismas víctimas y que luego fueron publicados como libros. A la luz de dichos escritos, se configura un entramado de reconfiguraciones. Por lo pronto -lo que es evidente-, se altera la finalidad de los lugares y también la percepción que de estos se tiene. Los detenidos dan cuenta expresa de dichas alteraciones, hablando de ellas y manifestando su sorpresa, incredulidad y tristeza. En segundo término, se operan cambios físicos de diferentes grados en la infraestructura de los espacios, y dichas alteraciones son llevadas a cabo, principalmente, por los mismos 
prisioneros, lo que es vivido dramáticamente. Son estas mutaciones y el modo como son experimentadas por los prisioneros lo que se analiza. Este modo de aparición de los centros de detención y/o tortura, con los efectos que ello tiene sobre los prisioneros, fue, sin duda, una estrategia consciente y concertada por la dictadura, por lo que debe incluirse entre los modos de tortura psicológica más efectivos.

\section{Cambio de finalidad}

El cambio, la transformación o reconfiguración de los lugares se verifica, en primer lugar, respecto de su finalidad y, por lo tanto, de su sentido. Los lugares que servían para morar, administrar, jugar, festejar, instruir, enseñar, curar y sanar, pasan a tener nuevas finalidades: privar de libertad, interrogar, torturar, forzar a trabajar, matar y hacer desaparecer. Los que en mayor medida notan y pueden dar cuenta de esta transformación son, sin lugar a dudas, quienes viven alguna experiencia en dichos lugares antes del Golpe de Estado y luego retornan a ellos en calidad de prisioneros o detenidos. Son sus testimonios los que permiten constatar la mutación y contrastar los lugares previos con los posteriores. Ellos son, también, los que en mayor medida se sorprenden con el cambio y a quienes les cuesta creer que haya tenido lugar; sobre todo si los testigos han mantenido alguna vinculación afectiva con los lugares. Vivenciar su transformación, además de sorpresa e incredulidad, les produce en la mayoría de los casos también dolor: sufren a raíz de ello, un sufrimiento provocado y buscado por los uniformados.

\section{Contraste y constatación}

Quienes conocieron los lugares antes y luego deben vivirlos desde dentro, cuando ya se han transformado en centros de detención y/o tortura, dan cuenta, a partir de los recuerdos, de la mutación. Para ellos es notorio el cambio, ya que tienen clara conciencia de lo que esos lugares eran antes del Golpe. Luego de ser torturado, Haroldo Quinteros relata que lo trasladaron al edificio de la Intendencia, donde se le aparecieron imágenes de experiencias pasadas. "Me sentaron en el gran salón de la Intendencia, donde una vez, recuerdo, siendo liceano recibí un premio de arte, donde Nora se lució como bailarina de ballet, donde no hacía ni tres meses agasajamos a una delegación cubana. El salón ahora estaba lleno de soldados y de mugre, y también de muestras de sangre" (69). Era el mismo lugar, pero ya no lo era: había cambiado, lo habían cambiado. La suciedad, la presencia de una gran cantidad de uniformados, pero, sobre todo, las manchas de sangre, son las marcas del cambio. Ahora es un lugar diferente: descuidado, tomado y, lo que es peor, utilizado para hacer sufrir.

Ibar Aibar nació en el norte, puntualmente en una oficina salitrera llamada Chile (1930), y de pequeño visitó Chacabuco. Luego se trasladó a Santiago, pero 
la represión y la dictadura lo llevaron nuevamente a su tierra natal, esta vez como prisionero. Comprobó, de inmediato, que no se trataba del mismo lugar: "Ahora en 1973, yo estaba nuevamente en Chacabuco. Todo era distinto" (17). Más adelante en su relato repite este juicio, pero lo explica más detenidamente: "Treinta años atrás, cuando esa salitrera luchaba aún por sobrevivir, conocí Chacabuco. Entonces visité su plaza verdosa de cuidados intensivos donde el agua no escaseaba. Visité la iglesia y el teatro. Ahora todo había cambiado. La desolación, el silencio y el polvo de los años, que lo cubría todo, eran únicos testigos de esos viejos monumentos" (39). El Chacabuco que era ahora un centro de detención, había perdido, sintomáticamente, el verdor y el agua, volviéndose reseco, desolado, abandonado y sin vida.

Cercana es la experiencia de Jorge Montealegre, quien estando en el Estadio Nacional evoca antiguos recuerdos de niñez: "Me veo corriendo con mi hermano Óscar, como dos barrabases ansiosos por entrar al Estadio para disfrutar de los octagonales en que jugaba Santos de Brasil, con Pelé y todo ese ambiente de fiestas. En una de esas aglomeraciones frente a las boleterías el guanaco nos mojó por primera vez. Pero esa represión era casi un juego" (43). Una suerte de "bautizo de represión" en el mismo lugar donde años después fue encerrado y torturado. Más adelante en su relato, ya desde el lugar del prisionero, escribe: "Me recuerdo mirando desde los baños hacia la entrada del Estadio. Me asomaba sin buscar a nadie, reconociendo el barrio. Había vivido muy cerca, compartiendo una pieza con mi hermano Óscar. Además tenía tías a pocas cuadras. En la casa de una de esas tías vivía la Nené. Todo era familiar y al mismo tiempo lejano" (164). La historia de Montealegre, su niñez ligada a un Estadio Nacional que se le vuelve ajeno, extraño, sin dejar de ser el lugar de sus recuerdos, es ahora otro lugar.

Algo similar le ocurre a Adolfo Cozzi en el mismo Estadio Nacional. Cuenta que lo condujeron, junto a otros prisioneros, a una puerta lateral por la que ingresaron a la cancha. "Me llamó la atención el verde brillante del pasto - esa mañana había sol y cielo azul-, evoqué la emoción que sentía de niño cuando salían los jugadores al campo, oí los gritos de las barras, el pitazo inicial del árbitro" (37). Nuevamente, el recuerdo de una niñez en el estadio. Otra vez, el contraste con la situación del que relata: "Entonces, en cada esquina de la cancha había una banderola que siempre me obsesionó cuando chico, porque no entendía cómo no le molestaba al jugador cuando lanzaba el córner. Ahora, en cambio, había una metralleta punto 30 servida por dos soldados tirados de guata en el pasto" (37-8). Un soldado y una metralleta en la esquina del córner, lista para disparar, pero esta vez ni un centro, ni un balón, sino muerte.

A Luz Arce la llevaron a Londres 38 y pese a estar vendada reconoció de inmediato el lugar. "Sentí que la camioneta ingresaba a un recinto cerrado. Escuché un ruido. Quedé sorprendida: era el mismo chirrido que hacía el portón de Londres 38 de la Octava Comuna del ps. Efectivamente, en ese local que había sido del Partido Socialista, funcionó el cuartel llamado Yucatán de la DINA" (55). Lo reconoce, como 
muchos otros detenidos, por las baldosas de la entrada ${ }^{4}$. Ella había estado innumerables veces allí, pues era la sede del partido en el que militaba (28). Estando en Londres 38, fue interrogada por un oficial; en ese momento, Arce cuenta: "[r]ecordé que en esa misma oficina de la calle Londres me había reunido una vez con Carlos Álamos. Lo imaginé en algún más allá fumando un oloroso Tiparillo. Volví a mirar al oficial” (111). El mismo lugar, pero ahora otro: en el lugar de su admirado superior, ahora un temido y odiado militar. Se le superponen a Arce el recuerdo con la realidad: la misma dirección, la misma casa, antes cede de su partido, ahora centro de tortura.

\section{Sorpresa e incredulidad}

Desde la perspectiva de Jorge Montealegre, el Estadio Nacional sufre, un cambio increíble, y para destacarlo el autor construye algo así como la historia de sus usos, en un capítulo de su testimonio que denomina significativamente "Estadio de Emergencia". Allí señala: "En sus años iniciales, el Estadio fue 'asilo contra la opresión’ cuando albergó a yugoeslavos, lituanos, polacos, húngaros y otras víctimas de la Segunda Guerra. Fue, lógicamente, el gran escenario de esa 'fiesta universal del deporte del balón', el ya mítico - para los chilenos- Mundial del 62” (42). El Estadio fue también, como apunta el autor, un lugar cívico, político, al punto que los presidentes eran evaluados allí: "Cuando lo merecía, y ninguno estuvo exento, la ciudadanía -el gran árbitro- sancionaba su falta con su voto. Y ese mismo lugar era recinto de votación" (42). Además, recuerda, fue donde el pueblo chileno recibió a Neruda con el Premio Nobel bajo el brazo (43). Ahora, había sido transformado en un lugar de prisión, tortura y muerte. El contraste con lo que había sido resulta brutal y, por lo mismo, aparece como sorprendente e inverosímil: de as ilo contra la opresión a presidio para la opresión. En este sentido, Benavente escribe en su testimonio que: "En un comienzo no le había sido fácil creer que, en el interior de las murallas del campo deportivo, anidara el terror y la tortura" (67).

Increíble por inverosímil es también para algunos el haber sido torturados en el Buque Escuela Esmeralda, conocido también como la "Dama Blanca". Sergio Vuskovic manifiesta, impactado al relatar su experiencia de tortura, que "todo esto se hizo tanto a hombres como a mujeres en el buque escuela de la Marina chilena” (70). Quien transcribe la declaración agrega entre paréntesis que hay una "interrupción". Dicha pausa, que es suficientemente extensa como para que quede registrada por escrito, puede leerse como una marca de la impresión del declarante, una constatación de que es simplemente increíble que el buque escuela de la Marina haya sido utilizado como lugar de tortura. Esto se corrobora cuando en el documental de Patricio Henríquez

4 "Cuando nos bajaron, con los tirones y los golpes se me corrió la venda. Algunas lágrimas mojaron la cinta adhesiva y cuando pude percibir por abajo las baldosas blanquinegras, estuve segura. Era Londres 38” (Arce 55). 
titulado El lado oscuro de la Dama Blanca, el mismo Vuskovic afirma: "y me torturaron en la Esmeralda”. Por su entonación, su gesto y el movimiento de su mano, se ve claramente que le interesa destacar lo insólito que le resulta el hecho, sobre todo, para un porteño. En el mismo documental, una ex prisionera dice textualmente: "yo me morí cuando supe que era la Esmeralda... ¡La Esmeralda, donde yo vine a recibir a mi primo hace dos años atrás!".

Al utilizarlos para encerar, para torturar, para matar, se mancilla la dignidad de los lugares; han sido profanados espacios que gozaban de un aura que les hacía queribles, incluso entrañables. Lugares donde se habían vivido experiencias atesorables. Lugares que tenían alguna dignidad, que habrían sido respetados, incluso amados, ahora son ensuciados. Sintomática es la reacción de Vuskovic en el documental, al referirse a La Esmeralda: "A mí lo que me da más rabia, es que le llamen la Dama Blanca”. La blancura, síntoma de ingenuidad, limpieza y pureza que en algún momento pudo haberle pertenecido a dicho barco, ya no le corresponde: ha sido manchada, mancillada. De allí el título del documental de Henríquez: "El lado oscuro de la Dama Blanca"; luego de la tortura, ya no es "dama" ni menos "blanca". Algo análogo ocurre, para Benavente, con Tres Álamos: "según se comentaba, el solar había sido un antiguo convento de monjas. Ahora se utilizaba en menesteres que nada tenían que ver con la solidaridad cristiana" (152).

Las mutaciones en los lugares no solo producen sorpresa e incredulidad, sino que desencadenan reacciones algo delirantes en los prisioneros: se cree, se sueña con estar en un lugar, cuando se está en otro. Montealegre, por ejemplo, cuenta que se siente "aliviado" cuando llega como prisionero al Estadio Nacional. "Con las manos en la nuca y la barbilla resentida llegué a la Recepción del campo de prisioneros más grande de Chile. Fue casi un alivio. Estaba en el Estadio Nacional. El mismo estadio donde había visto jugar al Santos, el equipo de Pelé, y me había reído con los muñecos gigantes de los clásicos universitarios" (41). ¿Cómo se puede sentir "alivio" al ser llevado a un centro de detención y tortura de la dictadura? Esto solo se entiende si atendemos a la asociación positiva que Montealegre tenía con ese lugar desde pequeño. En el documental Estadio Nacional de Parot (2001), Alberto Cozzi cuenta la anécdota de que cuando los prisioneros son sacados por primera vez a las galerías, pues había una visita de la prensa, tuvo la sensación, "por un instante, por una décima de segundo", al mirar el pasto, que iban "a salir los jugadores a la cancha y va a haber un partido aquí", para luego constatar: "no po, guevón, si estoy preso aquí".

\section{Frustración y sufrimiento}

Los cambios de finalidad de los recintos, además de sorpresa e incredulidad, provocan en algunos casos profundo dolor y tristeza. La dignidad mancillada de los lugares hace sufrir especialmente a aquellos prisioneros que tenían un vínculo con ellos. De esto son conscientes los militares, y lo utilizan. Según Nancy Guzmán, la selección de 
los lugares no fue azarosa, sino que "para acentuar el efecto psicológico de la derrota, se usaron como centros de tortura lugares que tenían cierta connotación histórica o política para los detenidos" (69). Guzmán menciona "el Estadio Nacional, Londres 38, José Domingo Cañas, Villa Grimaldi, Santa Lucía 162, la Universidad de Chile, la Casa de Piedra, las cabañas de playa de sindicatos y la casa de Los Plátanos" (70). Por supuesto podrían agregarse otros como La Esmeralda o Chacabuco. Para que este efecto se diera, para que cumpliera el cometido de "acentuar la derrota", era indispensable que el antiguo lugar perdurara, que permaneciera de alguna forma: era necesario que, por ejemplo, no se perdiera de vista que Londres 38 fue la sede del Partido Socialista, ni que dejara de tenerse en cuenta que Santa Lucía 162 lo era del MAPU. Del mismo modo, era preciso recordar que la casa que fuera de Theotonio dos Santos en José Domingo Cañas era ahora un lugar de tortura, y que la Casa de Piedra era del propietario del diario El Clarín. La Esmeralda fue, es y sigue siendo el Buque Escuela, y Chacabuco ya había sido declarado Monumento Nacional. Solo en tanto superposición de lugares se obtiene este efecto del que habla Guzmán.

Los cambios de finalidad y la dignidad mancillada de los lugares hacen sufrir no solo a quienes tenían una historia o un vínculo político con esos espacios, sino que especialmente a aquellos que mantenían un vínculo afectivo con ellos. Hasta el 11 de septiembre de 1973, el Cerro Chena era central para la comunidad de San Bernardo. Cuenta Ahumada que "El Chena era lugar obligado de visita para niños y jóvenes de la comuna [...] Familias completas se instalaban los fines de semana en primavera y verano en sus faldas, a un costado de la carretera Panamericana, a disfrutar de un día de esparcimiento entre los viejos árboles que entregaban sombra durante todo el día, no importando la ubicación del sol" (28). Señala el mismo Ahumada que una vez transformado en centro de detención y tortura, todo cambia: "El cerro Chena pasó de lugar de esparcimiento a centro de detención clandestino [...] Los militares, que formaban parte del paisaje de la ciudad, se transformaron en carceleros, torturadores y verdugos" (32). El autor no oculta su angustia al relatar esta mutación, es por ello que cierra su testimonio con un capítulo titulado “ ¿Chena volverá a ser lo que fue?” (177). La respuesta es condicionalmente negativa: solo podría volver a serlo el día en que se reconozca toda la verdad de lo allí sucedido. El capítulo tiene un fuerte tono nostálgico y se abre con la frase: "El cerro Chena, nuestro cerro para los sanbernardinos, no siempre estuvo asociado al terror y la muerte" (177). Lo que hace Ahumada es mostrar que, desde el Golpe, dicha asociación es inevitable y que el Chena nunca ha vuelto a ser aquel "lugar de encuentro de la población que yace a sus faldas" (178).

Aunque fuera utilizado para muchas cosas, el Estadio Nacional fue construido especialmente para servir como centro deportivo. Es por ello que para los deportistas, el que el máximo coliseo, aquella cancha en la que todo futbolista aspira a jugar algún día, fuera utilizado para detener, torturar y asesinar constituyó una absoluta violación. En el documental Estadio Nacional de Parot (2001), se relata la historia 
del Hugo "Choco" Lepe, quien había sido futbolista, incluso seleccionado chileno, y que estaba detenido. Francisco "Chamaco" Valdés, en ese entonces capitán de la selección chilena de fútbol, comenta de su visita al Estadio: "fue amargo y triste tener que entrar al Estadio Nacional, donde no hacía ni un mes que nosotros habíamos jugado aquí por el campeonato oficial, habíamos jugado partidos para la eliminatoria del Mundial del '74, y después tener que entrar acá y tratar de encontrar al amigo que estaba desaparecido". Un lugar de contiendas deportivas, de alegrías colectivas, de triunfos y derrotas, un lugar casi sagrado para los deportistas, que ahora había sido profanado: de allí el dolor, la tristeza de Valdés y de todos quienes estaban ligados al deporte.

Un caso paradigmático y extremo de dolor por la transformación de los lugares es el de Oscar Vega en Chacabuco. No deja un testimonio directo; sin embargo, son muchos los que hablan de él y su sufrimiento. Cuenta Jorge Montealegre de la violencia que produjo este cambio para Vega:

Lo apresaron y fue castigado, como todos los presos. Junto a otros nortinos estuvo "desaparecido" varios días. Después lo trasladaron a un campo de concentración: Chacabuco. Pero ya no era la oficina salitrera donde se partió las manos. La pulpería estaba cerrada, el teatro, la filarmónica y la plaza estaban distantes. Se interponía una frontera de alambres. En los fogones de las casas no había mujeres cocinando [...] En las noches la camanchaca era violada por reflectores intrusos. Todo era distinto (86).

También Mario Benavente se refiere a la agonía que experimenta Vega. Señala: "Después de muchos años en que pudo vislumbrar la esperanza de una vida mejor, volvía a sus raíces como prisionero de guerra. El dolor era su desgarramiento" (22). La nostalgia por el lugar que ya no es lo invade: su hogar está perdido para siempre, el espacio en que crió a sus hijos, donde comenzó su cruzada, ya no existe:

Cada pedrusco le hablaba de su juventud, de sus padres, abuelos, compañera e hijos. Todo estaba empapado de vivencias. Su mujer esperaba con la comida lista. Sus hijos volvían a correr descalzos por esas arenas. Los gritos de sus juegos y peleas llenaban el contorno. Allá iba él para alcanzarlos. Siempre se le escapaban. Eran inasibles. Deseaba abrazarlos, pero siempre se desvanecían bajo el azul de la pampa (22).

Vega llora esta distancia, este cambio, esta diferencia. Decide buscar la que había sido su casa muchos años antes, y allí se quita la vida colgándose de una viga. "El, chacabucano de ayer y de hoy, ya estaba de vuelta en casa. Nunca se vio salir de Serrano 71 la figura del obrero pampino. Sólo quedan las paredes semiderruidas del patio, los camarotes... y una viga rota" (Montealegre 87 ). 


\section{Alteraciones físicas}

La mutación fundamental de los lugares se da al nivel de su finalidad. Con el propósito de ser utilizados para sus nuevos objetivos -encerrar, torturar, asesinar, etc.-, algunos inmuebles fueron alterados además físicamente, aunque es necesario constatar la existencia no menor de instalaciones que se utilizaron sin intervención alguna. De hecho, un número importante de los lugares utilizados como centros de detención y/o de tortura simplemente no sufrieron cambios físicos. Esto parece reconocer al menos dos causas principales. Por una parte, se trataba de inmuebles ya habilitados, o suficientemente habilitados para estos fines. Es el caso de las cárceles, por ejemplo, o las dependencias militares o policíacas destinadas ya a la reclusión y retención de personas. Está también el caso de locaciones que, pese a no estar habilitadas específicamente para ello, cumplen con condiciones mínimas que hacen posible el control, por lo que se utilizan sin alterarlas físicamente. Es la situación, por ejemplo, de las bodegas de los barcos: allí se acumulan personas como antes se hacía con las mercancías, y como única habilitación se instalan en la mitad unos enormes tarros que habrían de servir de letrina: los "chutes".

Lo mismo podría decirse del Estadio Nacional: sus camarines y los túneles, así como la piscina, sirven bien como lugar de encierro; mientras que el velódromo se utiliza como espacio de interrogación y tortura. Algo similar es lo que ocurre con el Estadio Chile. En vistas de que se trata de lugares que se piensa utilizar solo temporalmente como prisión, no se interviene concretamente la dependencia. Esto, por supuesto, no quiere decir que no se den, en estos ejemplos, reconfiguraciones espaciales. San Francisco, Fuentes y Sepúlveda han mostrado claramente que en el Estadio Chile, hoy llamado Víctor Jara, "[e]l examen de la espacialidad y la arquitectura [...] dejan entrever una clara reconfiguración funcional y significativa de sus espacios con fines represivos durante los inicios de la Dictadura Militar en Chile" (111). Su funcionalidad y la significación de los espacios cambian, se reconfiguran, sin alterar para nada su estructura física.

Otros lugares, sin embargo, son efectivamente sometidos a transformaciones físicas. $\mathrm{Al}$ respecto, hay al menos dos asuntos diferentes pero vinculados que se pueden observar: uno referente a la magnitud y radicalidad de dichas transformaciones y otro concerniente a los agentes que las llevan a cabo. En efecto, es posible reconocer diferentes niveles de intervención en los lugares. Algunos de ellos debieron ser refaccionados del todo por encontrarse en mal estado o porque sus instalaciones no servían para la nueva finalidad, mientras que otros no fueron objeto casi de modificación alguna. En medio hay casos de alteraciones de diferentes grados. En cuanto a

5 Cuenta Jouí del Lebu que "[a] un costado de la bodega, habían colocado tres tarros grandes de aceite, desocupados, partidos por la mitad y con una tabla que los atravesaba de borde a borde. Eran los 'chutes' para cagar. Eran unos baños improvisados" (39). 
los agentes de transformación, se trata fundamentalmente de dos: los militares y los prisioneros, aunque hay casos en que participan contratistas civiles.

\section{Transformaciones menores}

Las transformaciones a las que son sometidos los centros de detención y/o de tortura reconocen muy diferente orden y profundidad. Entre ellas, las primeras que vale la pena mencionar son aquellas que constituyen simples arreglos menores, reparaciones, agregados, etc. que están destinados a habilitar un espacio. En este caso, se podría hablar, por una parte, de transformación estética o de aspecto, y por otra, de transformación para comodidad o funcionalidad.

Las transformaciones estéticas o de aspecto son arreglos o habilitaciones que afectan, en primer lugar, la apariencia de los inmuebles. Entre ellas están, por ejemplo, las labores de ocultamiento de los lugares: se tapian las rejas, se empavonan los vidrios. Los cambios de tipo estético afectan, sin embargo, también a cuestiones de un orden más positivo, sobre todo cuando quienes los realizan son los propios prisioneros: hacer del lugar algo más agradable, más amigable, más cómodo y bello. Un caso paradigmático es el que relata Alberto Gamboa de sus primeros días en Chacabuco. Cuenta que sus compañeros eran "expertos artesanos" (65) que hicieron todo tipo de reparaciones y construyeron el mobiliario necesario para la casa. Relata concretamente que le ayudaron a construir una repisa donde puso sus cuadros y útiles de aseo, e improvisó un atril donde ubicó las fotos de su familia.

De acuerdo con el relato de Lawner, lo mismo se observa en Dawson, donde "[a]provechando algunos trozos abandonados de madera prensada, confeccionamos pequeñas repisas o veladores al interior de la barraca, a fin de liberar espacio en las literas, receptáculo de todos nuestros efectos personales" (40). El mobiliario construido, en algunas ocasiones, alcanza altos grados de refinamiento, tal como cuenta el mismo Lawner: "Recurriendo a las varas de coigüe, el más abundante de los recursos disponibles, iniciamos la construcción de unas bancas corridas en el patio de nuestra barraca, donde estamos obligados a permanecer largas horas de pie" (40). Es el caso, también, del horno de barro en Chacabuco: "En el hogar 36, el trabajador porteño Víctor Bruna, obrero panificador, de Villa Alemana, había preparado 70 empanadas, en un pequeño horno de barro que había reconstruido algunos días antes. Las empanadas estaban hechas con charqui y cebollas" (Joui 86).

Hay algunos arreglos que, dejando de lado el tema estético, tienen que ver con cuestiones algo más estructurales y contribuyen también a hacer más llevadera la vida de los prisioneros. De lo que se habla aquí es de lo que en derecho civil de denominan "mejoras". Lawner cuenta, por ejemplo, que las barracas en Río Chico carecían de aislación, por lo que pusieron unas planchas de aislapol que envió la Cruz Roja (111). De esta forma, ante condiciones climáticas extremas, se hacía posible sobrellevar el frío intenso y el viento. 
Así como hay mejoras que hacen más agradable la vida de los prisioneros, las hay que buscan hacer más fáciles -o incluso posibles-algunos procedimientos, que facilitan la labor de los carceleros. Entre ellos, está el tema de, por ejemplo, preservar la "incomunicación" de algunos prisioneros. Es el caso de lo relatado por Rodrigo Rojas, quien cuenta que en la Penitenciaría "las rejas de acceso a las calles y galerías fueron tapiadas con planchas de zinc para impedir toda posibilidad de comunicación" (48). Hay relatos que dan cuenta del levantamiento de muros, de tapias, de separaciones. En su estadía como prisionero en Melinka, Joui expone que "[e]n la mañana vemos que unos Infantes de Marina empiezan a construir un cerco alto de madera que encierra la cabaña azul de Puchuncaví y cierra la mitad de los baños" (168). Se aísla y reserva una cabaña que será para los más altos dirigentes del Gobierno de la Unidad Popular, que llegarían desde isla Dawson. Algo parecido es lo que se hace en Chacabuco, según da cuenta Carrasco ${ }^{6}$, donde se preparaba un espacio para los prisioneros evacuados de Pisagua.

\section{Transformaciones mayores}

Además de estos cambios o mejoras, hay algunas transformaciones que deben calificarse de "mayores". Se trata de aquellas sin las cuales sería casi imposible que los inmuebles fueran utilizados para detener y mantener vigilados a los prisioneros. En este caso, se podría hablar de mejoras fundamentales o indispensables. Entre estas se cuentan, por ejemplo, aquellas que incorporan nuevas construcciones al interior de los lugares mismos. Para este tipo de transformaciones el mejor nombre sería el de ampliaciones, pero hay modificaciones mayores que van más allá de una simple ampliación y constituyen, en realidad, una refacción global o casi una reconstrucción completa del inmueble. Estamos aquí ante una transformación total.

Lo más corriente en términos de ampliación es la construcción de torres de vigilancia y la instalación de alambradas, lo que se repite en gran cantidad de lugares. Del Valle cuenta de Tres Álamos que "carabineros sólo tuvo que ponerle cuatro torres de control o casetas para los vigías y así quedó transformado en campamento para prisioneros políticos" (65). Carrasco señala que para transformar el "Balneario Popular de Puchuncavi" en el "Campo de Detenidos de Melinka": "La rodearon de doble alambrada de púas. Ocultaron la garita de la entrada con una trinchera de sacos de arena, al lado de las obras finales de las dos inmensas torres de palos y tablas cruzadas con reflectores y ametralladoras en sus plataformas donde vigilan los centinelas" (188).

Hablando también de Melinka, Durán cuenta que como se trataba de un Centro Recreacional, "los primeros prisioneros fueron obligados a construir una reja

6 "Un enrejado pequeño, dentro de un enrejado grande. Pocas semanas antes terminaron en Chacabuco la construcción de la empalizada y la nueva reja aislando de nosotros varios pabellones hacia el fondo" (Carrasco 183). 
doble con alambres de púas, dejando un espacio entre ellos para que los soldados plantaran minas. En las cuatro esquinas, habían construidos torres de vigilancia" (Autobiografía 90). Alberto Gamboa se detiene en su testimonio a pormenorizar las transformaciones que se hicieron a la exsalitrera de Chacabuco, para habilitarla. En cuatro semanas, según cuenta, se transformó Chacabuco en un campo de concentración: "Cerraron con rejas tipo gallinero, de más o menos tres metros de altura, el lugar donde estaban las casas de los obreros y empleados de las salitreras [...] A las rejas las coronaron con alambre de púas electrificado. Y construyeron altas torres de madera con techumbre, donde la guardia armada vigilaba día y noche a los detenidos para impedir que se escaparan" $(15)^{7}$.

El levantamiento de torres de vigilancia y alambradas no son las únicas construcciones que se llevan a cabo. En este marco, hay algunas intervenciones en los inmuebles que van desde el levantamiento de una pared y la modificación de estructuras completas, hasta la construcción de nuevas dependencias. Cuenta Durán, respecto de Tres y Cuatro Álamos, que “[e]l seminario era grande y tenía diferentes pabellones. Cuando lo transformaron en una cárcel, habían encerrado cada uno de los tres pabellones con murallas de cemento y habían puesto torres de vigilancia y alambres de púas sobre las murallas" (Autobiografía 72). En los testimonios también se informa de la construcción de nuevas dependencias al interior de los centros. En Villa Grimaldi, por ejemplo, se levantaron varias estructuras nuevas. Luz Arce relata que "[a]l lado norte de la pieza que ocupábamos con las chicas, había otra habitación similar. Comenzaron a construir ahí lo que la DiNA llamaba 'las cajoneras' y los detenidos, 'las casas Corvi' o las 'casas Chile"' (192). En este caso, en estricto rigor, no se trata de otra habitación, sino que, en la descripción de la misma Arce: "Eran una suerte de cajones muy pequeños donde un joven de aproximadamente un metro setenta sólo cabía sentado y con las piernas recogidas" (192-3).

La construcción de nuevas dependencias obedecía generalmente a razones vinculadas con la detención o la tortura. Hay, sin embargo, un par de casos excepcionales en los que dichas construcciones tenían como objetivo mejorar la vida de los prisioneros. Un ejemplo de ello es la mediagua que se construyó en Villa Grimaldi para albergar a las "quebradas" que colaboraron con la DiNA -Carola, Marcia y Luz-y que esta última llamaba "la casita". Luz Arce se refiere a sus paseos con Rolf Wenderoth: "Uno de esos días me mostró una 'casita'. Más allá de las rosas, junto a la torre, varios soldados armaban una mediagua. Dijo que era para nosotras. Que estaría lista en un par de días. Me explicó que tendría dos ambientes" (207). Mejor ejemplo es, sin embargo, la construcción de un nuevo pabellón en Tres Álamos. Al llegar allí se le

7 Más adelante, Gamboa repite la descripción: "En torno a las casas de la vieja salitrera pusieron una reja de tres metros de altura, que terminaba en una alambrada de púas, de cuatro corridas, totalmente electrificada. Construyeron, además, ocho torres de seis metros de altura, en las cuales se colocaba personal de vigilancia armado hasta los dientes, y como si fuera poco, sembraron un campo minado" (75-6). 
informa a Durán que el "lugar se estaba haciendo pequeño para todos los prisioneros que venían, así es que habían habilitado un complejo prefabricado, el pabellón C, en alguna parte del recinto para mantener a las mujeres, algunas de las cuales estaban ahí con sus niños" (Autobiografía 74). El hacinamiento es una constante en los centros de detención y en este caso la solución fue levantar una estructura prefabricada nueva. En otros, la construcción de otras cabañas o pabellones.

En términos de construcciones que busquen la comodidad de los prisioneros, hay que mencionar también las letrinas que fabricaron los presos de Dawson. "La posesión de algunos materiales nos anima a solicitar la autorización para construir letrinas más higiénicas, dado que nos repugna el uso de las existentes" (Lawner 39). También Vuskovic da cuenta de que: "Dirigidos por Lawner, Matte y Matus, comienzan a construir sus propios baños” (56). Pero el caso más extremo es, sin duda, la construcción de la cabaña de recreo y descanso que diseñaron y levantaron los prisioneros de Río Chico. "Desde que llegamos a Río Chico, resolvimos con Matus construir una sala de estar lo más acogedora que fuera posible, a fin de mitigar la depresión, originada por el siniestro entorno dispuesto para nuestro cautiverio. Agucé el ingenio para concebir una cabaña original" (Lawner 80). En un mes la habían levantado, con sus propias manos, un grupo de prisioneros. Vuskovic también relata que "[s]e nos permite construir en el patio una pequeña cabaña, que resguardaba de la lluvia y de las nevadas. Se hizo con cariño" (63).

El nivel más extremo de alteraciones físicas de los lugares es, con todo, la reconstrucción y refacción completa. Un caso paradigmático es la reconstrucción del Fuerte Rondizzoni que había sido habilitado como presidio y estaba completamente deteriorado por el abandono. Witker relata que "[s]e dispuso la rehabilitación de Rondizzoni, un antiguo presidio que estaba abandonado en la isla Quiriquina” (56). Habla este autor del trabajo intenso y cuenta que en precarias condiciones los prisioneros recuperaron el lugar. Una vez terminada la reconstrucción se inaugura con toda pompa: se monta un espectáculo mediático. Witker copia partes de la columna de un periodista que habría asistido al evento y reproduce el discurso del comandante: El comandante Henríquez Garat -ahora con el mando del crucero Prat, a quien se debe en gran parte lo que en ese lugar vimos los reporteros-, se los agradeció. Y el contralmirante Costa Bobadilla, también lo hizo. Recuerdo que el entonces jefe de Estado Mayor les dijo a quienes construyeron el inmueble Rondizzoni: “Tengo un encargo del almirante: él se ha mostrado gratamente impresionado. La Comandancia, el que les habla, los oficiales y personal civil que ha participado en la construcción de este nuevo establecimiento, me han hecho llegar el reconocimiento por el esfuerzo desplegado por todos ustedes. Y -concluyó-: La construcción de Rondizzoni se hizo en cuatro meses de trabajo. Se hizo para darles las comodidades que ustedes merecen como seres humanos. Más adelante iremos mejorando esto" (57). 
Está, finalmente, el excepcional caso de aquellos lugares que fueron construidos especialmente para albergar prisioneros de guerra, para torturarlos, hacerlos trabajar en algunos casos y hacerlos desaparecer, en otros. Es lo que ocurre, por ejemplo, con el campo de concentración de Río Chico, en la Isla Dawson. Cuenta Sergio Vuskovic que "[e]1 19 de diciembre de 1973 somos transferidos al campo de concentración de Río Chico, la primera obra pública del régimen. Días antes había venido una delegación militar a inaugurarla. Estaban satisfechos: era un verdadero campo de concentración, pero a la chilena. En efecto, al poco tiempo el viento derriba una barraca que estaba por terminarse" (70). Constaba de cinco barracas llamadas Alfa, Bravo, Charlie, Remo e Isla y fueron construidas por los marinos. Existe de hecho un breve video en que se documenta dicha construcción ${ }^{8}$. Comenta Lawner que:

Rápidamente, circula el rumor de que Walter Rauf ha asesorado a los militares chilenos en el diseño del nuevo campo. Este asesino nazi, refugiado en Punta Arenas, donde ejercía la gerencia de una empresa conservera, puede efectivamente haber colaborado con sus émulos chilenos, pero carecemos de evidencias para afirmarlo con certidumbre. El rumor se originó entre algunos de los obreros contratados para ejecutar las obras, y que informaron sobre las visitas reiteradas de un ciudadano con acento extranjero, acompañando a los oficiales chilenos encargados de fiscalizar las faenas (74).

Otro caso de construcción es el campo de concentración Isla Riesco, levantado por los presos del buque Lebu al interior de un fundo en el llano Lliu Lliu, valle de Colliguay, en un terreno que sería propiedad de la familia Matte. No existen imágenes de este lugar, pero hay un plano en el testimonio de Joui (155). Según relata este autor, "se habían instalado 36 mediaguas con capacidad para 12 personas, o sea podía tener detenidas a 432 personas" (156).

Hay un tercer inmueble construido especialmente. Se trata de uno que se habría levantado en Pisagua. En "Construcción e instalación del campo de concentración de Pisagua”, uno de los capítulos de su testimonio (121-2), Alonso relata que los trabajos se iniciaron en octubre del 1973 y en diciembre ya se habían terminando. Como informa el mismo Alonso, "este campo no se pudo usar por los prisioneros de guerra, debido a las denuncias hechas por el ex prisionero de guerra, doctor Alberto Newman, en Naciones Unidas, como también debido al respaldo de los periodistas alemanes orientales que vinieron a Pisagua haciéndose pasar por periodistas de Alemania Occidental" (122). De esta construcción informa también Haroldo Quinteros, cuando se refiere a la existencia de un sujeto extraño que habría asesorado en la construcción del campo: "Y era alemán, un ex-nazi, contratado por el ejército para construir un campo de concentración, en el cual me tocó hacer trabajos forzados" (70).

8 Cf.: https://www.youtube.com/watch?v=mP-OPvgVL68 


\section{Constructores y obreros}

Las alteraciones, arreglos, refacciones, mejoras y construcciones de las que se ha hablado se llevan a cabo fundamentalmente por dos agentes: los mismos uniformados o los prisioneros, aunque hay algunos casos en que intervienen civiles. En los testimonios, por supuesto, se acentúa la participación de los prisioneros y tan solo esporádicamente se menciona que sean los uniformados quienes tienen un papel activo. Una excepción la constituye el relato que hace Alberto Gamboa al comenzar su testimonio, pues habla de que en Chacabuco "conscriptos de los regimientos de la zona, con ciertas habilidades de carpintería, la habilitaron y transformaron en campo de concentración, en algo así como cuatro semanas" (15). Igualmente, son soldados los que construyen la mediagua en que habitaría junto a Marcia y Carola en Villa Grimaldi (Arce 207).

Lo que más aparece en los testimonios es que los mismos detenidos, ya sea motu proprio u obligados, fueron los que trabajaron en la transformación o construcción de los centros. Alonso informa que los trabajos de construcción e instalación del campo de concentración de Pisagua fueron ejecutados por "los mismos prisioneros de guerra" (121-2). Joui indica que el campo de concentración Isla Riesco o Melinka fue construido por los presos del buque Lebu (156). Respecto de la rehabilitación del presidio en Isla Quiriquina, Witker apunta que "[c]omo parte del refinamiento del trato psicológico dado a los prisioneros, la superioridad de la Armada dispuso que estos trabajos fueran realizados por 'brigadas voluntarias' de prisioneros políticos. En medio de la tensión que se vivía, era evidente que negarse a trabajar en tales faenas significaba un desafío cargado de las peores consecuencias" (56). Relata Durán que don Tomás "[h]abía sido uno de los primeros en llegar a Puchuncaví. Los primeros prisioneros tuvieron que construir sus propios confinamientos y los nuestros" (Autobiografía 87). Con detalles da cuenta de la forma en que los prisioneros pusieron las rejas con alambres de púas y fabricaron las torres de vigilancia. Concluye su discurso con una frase terrible: "Habían trabajado para construirse su propia jaula [...] Debió haber sido un castigo, un trabajo desagradable y al mismo tiempo amenazante [...] estaban lentamente enjaulándose" (90).

Hay una diferencia entre contribuir a la construcción de la propia jaula y trabajar para hacer de la jaula un lugar más vivible. Aunque Gamboa reconoce que Chacabuco fue habilitada por los uniformados para ser usada como campo de prisioneros, aclara que: "Lo que importa reseñar es que fueron los detenidos los que transformaron, al correr de los meses, esa salitrera inhóspita en un lugar donde cada hombre cumplió una tarea" (78). Del mismo modo, fueron los prisioneros los que aislaron con planchas de aislapol su propia cabaña en Dawson: "Comenzamos la colocación de las planchas por la cara interior de los muros. Se trata de recortarlas con serrucho para aplicarlas en cada uno de los casetones que deja el entramado de madera. Tratamos de ajustarlas con la mayor exactitud en cada espacio, a fin de disminuir las fugas térmicas" (Lawner 111). La construcción más fabulosa realizada por los prisioneros de la que 
se da noticia en los testimonios es, sin duda, la del llamado Caiquén Dorado: cabaña de esparcimiento en Río Chico:

Trabajamos apasionadamente levantando los muros y el envigado de la techumbre, construidos con varas de coigüe de diferentes diámetros, debidamente ensambladas y clavadas, a fin de resistir los vendavales de la región.

Resolvimos dotar la cabaña con una chimenea, dado que en un espacio cerrado era imposible calentarnos con las fogatas [...]

Equipamos la cabaña con bancas, sillas y una mesa de centro, mobiliario ejecutado con nuestras fieles varas de coigüe. Proyectamos dos rincones para mesas destinadas a la práctica del ajedrez, o a la escritura de correspondencia. En las ventanas, reemplazamos el vidrio con un plástico grueso, obtenido de bolsas de envase dadas de baja. El recinto se pavimentó con una capa de gravilla apisonada, que trajimos en carretilla desde la orilla del estrecho.

Al cabo de un mes concluimos las faenas (Lawner 80).

Parece ser absolutamente excepcional, pero existe el caso en que se contrata a personal civil especializado para hacer los trabajos de reparación, transformación o construcción en los inmuebles. Uno de estos casos es el campo de Río Chico, que fue completamente levantado, al parecer, por civiles. Lawner habla de "operarios" (71) y de los "obreros contratados para ejecutar las obras" (74).

\section{Reconfiguración}

Se sostenía, al comenzar este texto, que el modo en que se generan los centros de detención y/o tortura de la dictadura chilena, es decir, la manera en que se constituyen, es fundamental y casi exclusivamente el de la reconfiguración. En otras palabras, se afirmaba que prácticamente ninguno de ellos fue creado explícitamente para ser usado como tal, sino que fueron el resultado de una serie de mutaciones, de transformaciones. Cambios en diferentes sentidos. Dos de esos cambios son los que sirvieron para articular este discurso.

Por una parte, se ha hecho ver la situación indesmentible de que se altera la finalidad de los lugares y, con ello, su percepción. Los lugares que servían para morar, administrar, jugar, festejar, instruir, enseñar, curar y sanar, pasan a tener nuevas finalidades: privar de libertad, interrogar, torturar, forzar a trabajar, matar y hacer desaparecer. A la luz de los testimonios, se puede observar que los prisioneros -especialmente los que tenían una vinculación anterior con el lugar- constatan y sufren este cambio. Ellos reaccionan con sorpresa, con incredulidad, al constatar que lugares que fueron apreciados, que contenían cierta dignidad son simplemente mancillados al transformarse en espacios de horror. A la sorpresa e incredulidad siguen, por lo tanto, el dolor y el sufrimiento por el daño causado a dichos espacios. 
En segundo término, como se ha podido observar, se operan cambios físicos en diferentes grados sobre su infraestructura. Hay lugares que son intervenidos solo estéticamente o con mejoras menores; hay otros que sufren cambios un poco más importantes, desde ampliaciones hasta llegar a los casos de refacción completa e incluso al de una construcción desde cero. Dichas labores las realizan, en la mayoría de los casos, los propios detenidos, quienes además de hacerlo con el objetivo de hacer más llevadera su prisión, se ven enfrentados a la paradoja de construir su propia prisión.

Sería sin duda un error negar la intencionalidad en esta estrategia de la dictadura. La reconfiguración como modo de llegar a ser de los centros, presentó para ella ventajas claramente buscadas que no pueden dejar de observarse. La utilización de lugares existentes tiene, por supuesto, en primer lugar, algunas ventajas económicoprácticas, pues con un costo muy menor se puede disponer rápida y eficientemente de un gran número de lugares para encerrar, torturar y hacer desaparecer personas. Las modificaciones, como se ha visto, son en su mayoría de menor cuantía y rápidas de implementar: en cosas de semanas, días o incluso de inmediato se podía comenzar a utilizar un inmueble como centro de detención y/o tortura. Con ello se evitaba todo el gasto, la demora y, por supuesto, la exposición que implica la construcción completa de un lugar especial.

Las ventajas son, por esto mismo, estratégicas, pues la reconfiguración permite conservar un bajo perfil, un anonimato y, con ello, la clandestinidad tan buscada por lo órganos de la dictadura. La utilización de lugares ya existentes a los que se interviene levemente -lo menos posible- no llama la atención de la prensa, ni siquiera de los vecinos, como si lo haría la construcción de un inmueble. Del mismo modo, se hace mucho más fácil su abandono. Es bien sabido que las casas de seguridad una vez "quemadas", es decir, descubiertas, eran abandonadas por los organismos de seguridad y reintregradas al mercado de bienes raíces sin mayor trámite. Tal vez el Estadio Nacional sea el mejor ejemplo de esto, pues tras ser utilizado con centro de detención y tortura un par de meses, es desocupado en cosa de días para que pudiera jugarse un partido de fútbol entre Chile y la Unión Soviética por la eliminatoria del Mundial.

Tal como insinúa Nancy Guzmán, las ventajas más importantes que obtiene la dictadura al utilizar inmuebles existentes son, sin embargo, de orden político-afectivo. Como explica la periodista, se ahonda la sensación de derrota al ser utilizados como centros algunos inmuebles significativos para los prisioneros. Dicha significación puede ser política, como lo indica Guzmán, pero también es de orden afectivo, como muestran los testimonios. La frustración, la tristeza y el dolor se extreman cuando lugares queridos, estimados, recordados, se usan para encerrar y torturar. Por otra parte, lo que se hace evidente a la luz de lo testimonios es que se ahonda aún más dicha sensación de desazón y derrota, si son los mismos prisioneros los que deben introducir las modificaciones en los lugares para transformarlos en su propia prisión. Los textos de los prisioneros dan clara cuenta de la enorme pena y frustración de los prisioneros al ser enfrentados al hecho de que lugares atesorados por ellos son 
mancillados descaradamente y que parte de dicha labor la llevan a cabo ellos mismos. Se provoca así una profunda herida en los detenidos, una que sin duda habría que alinear junto a las cicatrices de la tortura.

\section{Referencias}

Ahumada Lillo, Manuel. Testimonio: Cerro Chena - un campo de prisioneros. Santiago: Leonardo Sepúlveda producciones gráficas, 2011. Impreso.

Aibar Varas, Ibar. Sol y cielo abonaron mis sueños infinitos. Santiago: Emege Comunicaciones, 2002. Impreso.

Alonso Oyanedel, Freddy. La verdad de Pisagua: 1973-1974. Iquique: Colección Campus UAP, 2004. Impreso.

Arce, Luz. El Infierno. Santiago: Planeta, 1993. Impreso.

Bonnefoy, Pascale. Terrorismo de estadio: prisioneros de guerra en un campo de deportes. Santiago: Ediciones Chile América (CESOc), 2005. Impreso.

Benavente Paulsen, Mario. Contar para saber: Chacabuco, Puchuncaví, Tres Alamos (1973-1975). Santiago: JyC producciones gráficas, 2003. Impreso.

Camus, María Eugenia. "Puchuncaví, Ritoque, Tres Álamos: La otra cara de los campos de concentración”. Análisis xII (1989): 33-37. Impreso.

Corvalán, Luis Alberto. Viví para contarlo. Santiago: Ediciones Tierra Mía, 2007. Impreso. $^{9}$

Cozzi Figueroa, Adolfo. Estadio Nacional. Santiago: Sudamericana, 2000. Impreso.

Durán, Carlos. "Estadio Nacional: Memoria Nacional". Ciudad y Memorias: Desarrollo de sitios de conciencia en el Chile actual. Santiago: Corporación Parque por la Paz Villa Grimaldi, 2011. 148-156. Impreso.

Durán, Claudio. Autobiografía de un exjudador de ajedrez. Santiago: Lom, 2003. Impreso.

Escobar, América. Memoria y materialidad Londres 38: Un estudio de caso. Tesis para optar al título de Antropóloga, Departamento de Antropología y Sociología, Universidad de Concepción, 2011. Impresa.

Estadio Nacional. Dir. Carmen Luz Parot. Soledad Silva y Carmen Luz Parot, 2002. Fílmico.

Fuenzalida, Nicole. "Villa Grimaldi, análisis de la configuración del espacio y arquitectura, en relación a las estrategias de represión y control de los cuerpos de detenidos y torturados. Hacia una Arqueología de la Represión Política en Chile". Informe de Práctica Profesional, Departamento de Antropología, Universidad de Chile, 2009. Impreso.

9 Publicado originalmente bajo el título de Escribo sobre el dolor y esperanza de mis hermanos. Praga: Sofia Press, 1976. Impreso. 
Gamboa, Alberto. Viaje al infierno. Santiago: Editorial Forja, 2010. Impreso.

Geis, Irene y Pamela Jiles. "Campo de Concentración: Tortura y muerte en la Villa Grimaldi”. Análisis viI (1979): 30-34. Impreso.

Guzmán, Nancy. Olderock: La mujer de los perros. Santiago: Ceibo, 2014. Impreso.

Joui, Sadi Renato. Chacabuco y otros lugares de detención. Santiago-Valparaíso: autoedición, 1994 y 2003. Impreso.

Landaeta, Romané. "Centros de Tortura en Chile 1973-1990: Aproximaciones hacia una Arqueología del horror. El caso de Londres 38”. Historia y Memoria: Reconstrucciones de la represión en Chile: 1973-1974: El caso de Londres 38. Memoria Universidad Autónoma de Madrid, 2007. Impreso.

Lawner, Miguel. Retorno a Dawson. Santiago: Lom, 2004. Impreso.

Lazzara, Michael. "Dos propuestas de conmemoración pública: El Museo de la Memoria y los Derechos Humanos y Londres 38 (Santiago de Chile)". A contracorriente 3.8 (2011): 55-93. Impreso.

Montealegre, Jorge. Frazadas del Estadio Nacional. Santiago: Lom, 2003. Impreso.

---. "La casa de la viga rota". Chacabuco voces en el desierto. Ed. Carlos Cerda. Santiago: Pehuén /Goethe Institut, 1994. 85-88. Impreso.

Moret, Zulema. "La violencia del lugar". Aisthesis 48 (2010): 218-228. Impreso.

Pulgar, Claudio. "Lugares de Memoria y Olvido: El derecho humano a la ciudad". Ciudad y Memorias: Desarrollo de sitios de conciencia en el Chile actual. Santiago: Corporación Parque por la Paz Villa Grimaldi, 2011. 110-118. Impreso.

Pulgar, Claudio y Walter Imilan. "Un enfoque territorial para el estudio de espacios de memoria". Ciudad y Memorias: Desarrollo de sitios de conciencia en el Chile actual. Santiago: Corporación Parque por la Paz Villa Grimaldi, 2011. 181188. Impreso.

Quintero, Haroldo. Diario de un preso político chileno. Madrid: Ediciones de la Torre, 1979. Impreso.

Rojas, Rodrigo. Jamás de rodillas (Acusación de un prisionero de la junta fascista de Chile). Moscú: Novosti, 1974. Impreso.

San Francisco, Alexander, Miguel Fuentes y Jairo Sepúlveda. "Hacia una arqueología del estadio Víctor Jara: Campo de detención y tortura masiva de la dictadura en Chile (1973-1974)". Revista de Arqueología Histórica Argentina y Latinoamericana 4 (2010): 91-116. Impreso.

---. "Espacios de represión, lugar de memoria: El estadio Víctor Jara como centro de detención y tortura masiva de la dictadura en Chile". Revista AtlánticaMediterránea de Prehistoria y Arqueología Social 11 (2009): 137-169. Impreso.

Silva, Macarena y Fernanda Rojas. Sufrimiento y desapariciones: El manejo urbanoarquitectónico de la memoria urbana traumatizada. Seminario de investigación, Facultad de Arquitectura y Urbanismo, Universidad de Chile, 2004. Impreso. 
---. "El manejo urbano-arquitectónico de la memoria urbana traumatizada”. Ciudad y Memorias: Desarrollo de sitios de conciencia en el Chile actual. Santiago: Corporación Parque por la Paz Villa Grimaldi, 2011. 78-84. Impreso.

Vuskovic, Sergio. Dawson. Madrid: Meridion, 1984. Impreso.

Witker, Alejandro. Chile: Prisión en Chile. México: FCE, 1974. Impreso.

Recibido: 14 enero 2016 Aceptado: 21 septiembre 2016 